\section{Dealing with drug-seeking behaviour}

Aust Prescr 2016;39:151

http://dx.doi.org/10.18773/austprescr.2016.074

In the article dealing with drug-seeking behaviour, I was surprised to see no mention of Drugs and Poisons Information System Online Remote Access (DORA). It is a Tasmanian state-wide register that allows doctors to notify concerns about a patient's medicine use and ensures all subsequent prescriptions for drugs of concern are listed. Pharmacists can also access this information. I believe that at least one other state runs a similar system.

In the first instance, checking to see if an individual is registered on DORA will allow the prescriber or dispenser to establish if there are conditions already in place. This is very useful out of hours when contacting GPs is often not possible.

Secondly, DORA allows 'no fault' registration. Once an individual is registered on the system as 'of concern', it does not affect them in any way, and prescribing and dispensing continues as normal. However, their primary doctor or local emergency department can simply keep an eye on what is happening, and have the data to move to the next stage if necessary. It can also be useful for noting past issues and adjusting prescribing accordingly, opening the way for frank discussion, and reducing the risk of unwise prescribing in those with a history of addiction.

Fiona Wallace

Career medical officer

Mersey Community Hospital

La Trobe

Tasmania

\section{REFERENCES}

1. James J. Dealing with drug-seeking behaviour. Aust Prescr 2016;39:96-100. http://dx.doi.org/10.18773/ austprescr.2016.022
Jenny James, the author of the article, comments:

$\longrightarrow$ The author rightly draws attention to DORA and its potential benefits. Currently Tasmania is the only state to have a real-time electronic system for reporting and recording of controlled drugs.

The Australian Government has committed funding to set up a national system. If this system is well designed, it will have the potential to improve the quality use of opioids and other drugs of dependency prescribed in general and specialist practices. Potential benefits include a reduction of inappropriate prescribing and subsequent adverse events, promotion of a more patient-centred approach to the quality use of opioids, and encouragement for prescribers to move towards a more holistic approach in pain management.

There are some potential unintended consequences including doctors avoiding the use of Schedule 8 drugs in appropriate situations such as palliative care, greater stigmatisation of an already marginalised group of patients, and people changing their pattern of drug misuse towards illicit drugs or other prescribed psychotropic medications. An evaluation of a national system will be an important part of this process. 